\title{
SPEED CONTROL IN ELECTROMAGNETIC SYNCHRONIZATION SYSTEM WITH TWO SINGLE- Phase INDUCTION Motors By Rotor FluX REGULATION
}

\author{
Ali S. Akayleh \\ Department of Electrical Power Engineering and Mechatronics Faculty of Engineering, \\ Tafila Technical University Tafila, Jordan
}

\begin{abstract}
This paper focuses on the modelling, simulation and analysis of the behaviour of the electromagnetic shaft synchronization system with two identical single-phase induction motors. Motors speed-control and their synchronization are achieved by this electromagnetic shaft. A mathematical model has been suggested to describe this synchronization system. The traditional electromagnetic shaft synchronization system has been modified by adding an adjustable air-gap within the core of the three-phase inductive rheostat element in the common rotor circuit. The length of this air-gap is adjustable. This makes the use of the electromagnetic shaft more flexible. This makes it possible to control the speeds of the motors and regulate the synchronization capability or the recovery time of the system response (quality indicators). The quality indicators of the proposed synchronization system have been analysed. The suggested system has been mathematically modelled and simulated using MATLAB/Simulink. The proposed system has been tested for various load conditions. Results of the steady state and dynamics of the electromagnetic shaft synchronization system have been illustrated.
\end{abstract}

\section{KEYWORDS}

Electromagnetic shaft, variable air-gap, multiple-motor synchronization system, single-phase induction motor, recovery time, synchronization capability

\section{INTRODUCTION}

Multi-motor systems in different applications have become a very attractive in industries replacing the traditional mechanical coupling between different motors. Multi-motor techniques are used where matching the speeds is required between at least two motors during starting, acceleration, deceleration and changes in loads [1]-[3]. Such systems may be found in textile industry, paper machines, cranes, drug production lines, offset printing, reel machines, computer numerical control machines and other applications [4]-[20]. The most popular among the traditional speed synchronization systems are synchronization systems with electromagnetic shaft [4], [5]. The electromagnetic shaft system consists mainly of two identical motors connected together by a common additional external three-phase inductive rheostat element (RL-element) in the rotor circuits as shown in Fig. 1. 


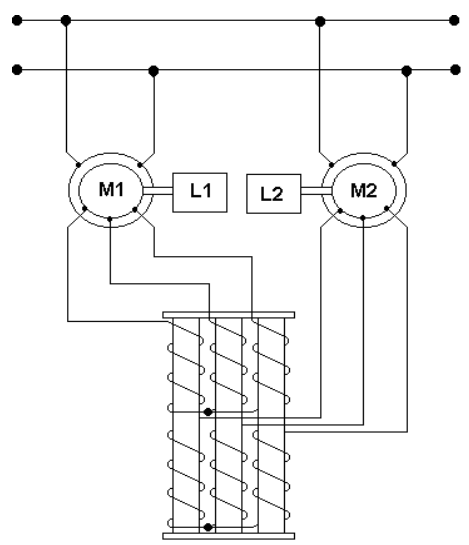

Fig. 1. Electromagnetic shaft system with single-phase induction motors

The operation of such synchronization systems is based on the principle of electromagnetic transformation of energy. Each of the two motors, in this system, is connected to three-phase wounded coils on a soft-iron ferromagnetic cylindrical cores, which are very similar to the transformer connection. One group of these coils (the primary coils) is connected to the rotor circuit of one motor and the other group (the secondary coils) is connected to the rotor of the other motor [2], [4] and [5].

When the currents in the rotor circuits flow towards both sides of the RL-element, the main motor coils fall under a correspondent and continuous influence of the power. Therefore, the change in one rotor current of one motor leads to a change in the rotor current of the other motor. So, the rotor currents flowing through the additional three-phase RL-element will be equal in case if the loads on both motors are equal. And the electromagnetic fields generated in this three-phase RLelement are equal in magnitude and opposite in direction, so the motors are operating as individual induction motors. If the loads are different, then the rotor currents and the produced electromagnetic fields will also change. Then the rotor current of the heavily loaded motor will be greater than the rotor current of the lightly loaded motor. Consequently, the produced electromagnetic fields in the three-phase RL-element will be opposite in direction and different in magnitude. In this case, the magnetic field of the motor with higher load will penetrate the RLelement side, connected to the lightly loaded motor, and will induce in it counter electro-motive force. This will slow down the lightly loaded motor until the speeds of both motors will be equal. In [11]-[13], speed synchronization of multi-motor systems had been studied. In [13] author is paying attention to the application of adjustable speed induction motor drives for gantry cranes. Solutions for load distribution in multi-motor drive, as well as mode of gantry drive skew elimination, are described. Authors in [12] described the speed synchronization of a DC multimotor system, while the DC motors, in the recent years, are rarely used because of their disadvantages compared to the induction motors. Many researchers studied such synchronization systems using three-phase induction motors [1], [11], [14], [15].

Because of the random-like but limited nature, chaos has been positively used in many industrial applications [16], [17]. In [16] authors studied the chaotic speed synchronization control of multiple induction motors using stator flux regulation. In [17] attention is paid to permanentmagnet synchronous motors chaoization using stator flux regulation. Some researchers have proposed control methods that use a hybrid system and fuzzy logic as a methods for analyzing and managing of different applications of speed control [21]-[24]. Much less studies may be found with single-phase induction motors [2], [3], [14], [18]-[20]. Therefore, in the current paper, the attention will be paid to synchronization system with single-phase induction motors. 
In this paper, a mathematical model is suggested to describe the synchronization system with two identical single-phase induction motors. It represents a synchronization drive with electromagnetic system by using a three-phase inductive rheostat element (RL-element) with variable air-gap within its core (Fig. 2). This air-gap will serve as a control element of the speed in order to enhance the system performance. Therefore, by changing the length of this air gap, the electromagnetic coupling between the two motors will be affected, and consequently, their speeds also.

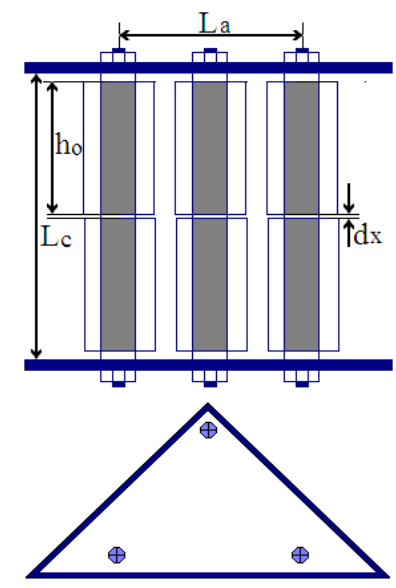

Fig. 2. Three-phase inductive rheostat element (RL-element)

Fig. 2 shows the three-phase inductive rheostat element (RL-element). The three cylindrical ferromagnetic cores (three arms) are located at the same distance from each other (La). Therefore, their base and top make a triangle shape, as shown in the lower part of the Fig. 2. These three arms have a length of (Lc). Each arm is divided into two equal parts, each of (h0) length. The two parts are separated by an air gap (dx). This air gap is variable and may be adjusted to get better performance of the system. Two groups, Y-connected three-phase coils are wounded around the ferromagnetic cylindrical cores, which are very similar to the transformer connections. One group of these coils is connected to the rotor circuit of one motor and the other group is connected to the other motor. These three-phase coils create the mutual inductance between the two motors. These windings are responsible of the synchronization capability of the system.

\section{EQUIVALENT CIRCUITS AND SYSTEM MODELING}

In order to analyze the suggested system, a mathematical model is proposed. The additional threephase RL-element in the common rotor circuit of both motors, the forward and backward sequence circuits are considered in the proposed mathematical model [4], [5]. Considering the first motor as master motor and the second motor as slave, the forward and backward equivalent circuits can be designed as shown in Fig. 3, where: EF2, EB2 are the forward and backward induced voltages in the rotors of the motors respectively; I11F, I21F are the forward currents in the stator circuits; I21F, I22F are the forward currents in the rotor circuits; I11B, I12B are the backward currents in the stator circuits; I21B, I22B are the backward currents in the rotor circuits; $\mathrm{R} 1, \mathrm{X} 1$ are the resistance and inductive reactance of the stator winding of both motors; $\mathrm{R} \mu, \mathrm{X} \mu$ are the resistance and inductive reactance of the magnetization branch of the motors respectively; $\mathrm{RK}, \mathrm{XK}$ are the resistance and inductive reactance of the common rotor respectively; $\mathrm{XC}$ is the capacitive reactance of the starting capacitor in the stator circuit; RM, XM are the resistance and inductive reactance of the RL-element respectively; $\Delta \alpha=\alpha 1-\alpha 2$ is the angular position between the stator and rotor winding of the motors respectively; $S$ is the slip of the motor. In the given 
equivalent circuit of the system both reactances of the two groups of coils are considered as $\mathrm{XM}=\mathrm{XM} 1 \pm \mathrm{XM} 2$, Where XM1 is a natural effect of the mutual inductance between the two coils on the same rod and the XM2 is the mutual inductance effect, which is related with changes in the value of $\mathrm{dx}$.

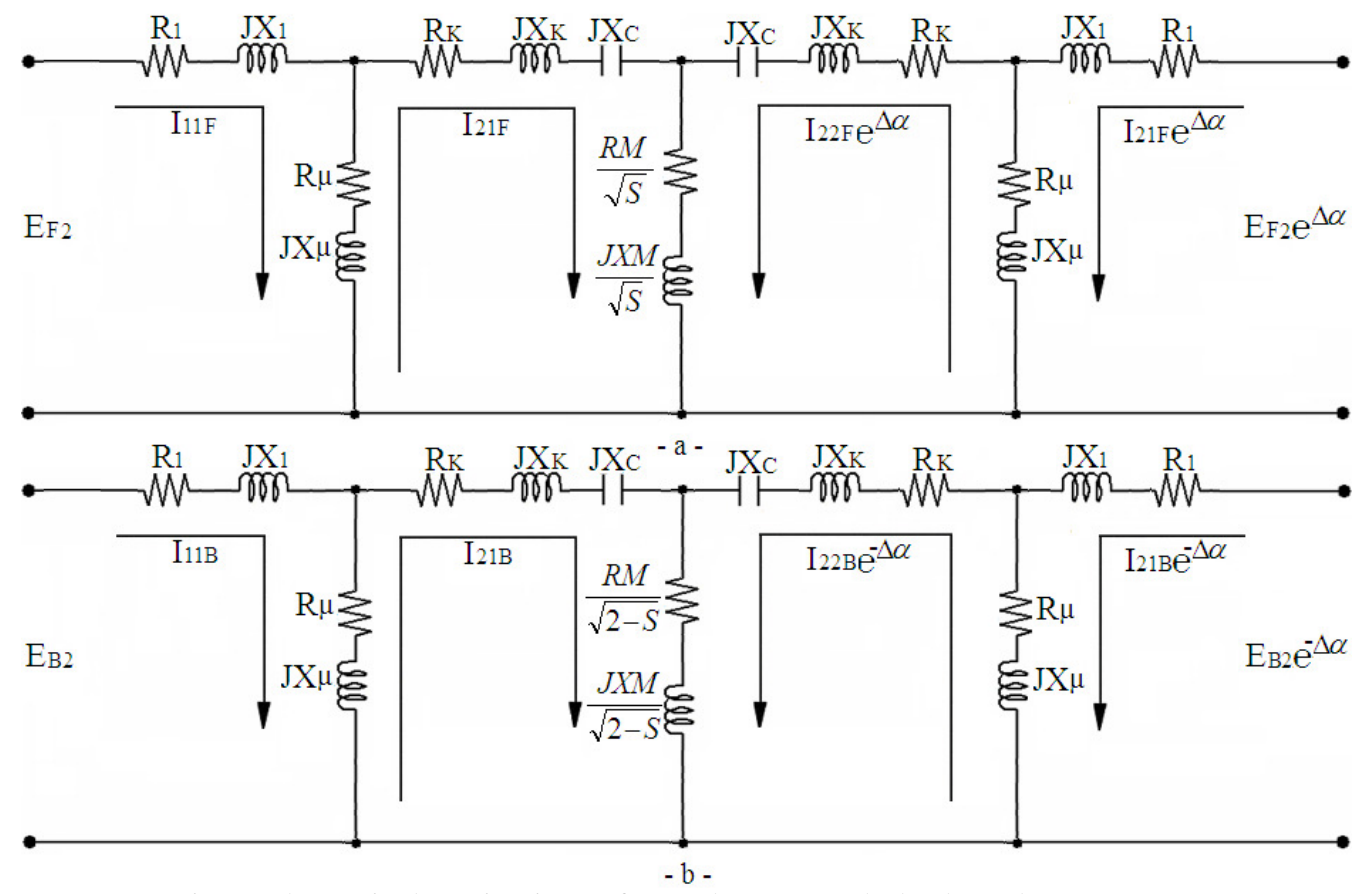

Fig. 3. The equivalent circuits: a) forward sequence, b) backward sequence

The balance equations for the phase voltages of the rotor of forward equivalent circuit can be calculated as follows:

$$
\begin{aligned}
& E_{2 F}=I_{11 F} Z_{S}-I_{21 F} Z \mu \\
& E_{2 F} \ell^{\Delta \alpha}=I_{12 F} \ell^{\Delta \alpha} Z_{S}-I_{22 F} \ell^{\Delta \alpha} Z_{\mu} \\
& I_{21 F} Z_{R}+\left(I_{21 F}-I_{11 F}\right) Z_{\mu}+\left(I_{21 F}+I_{22 F} \ell^{\Delta \alpha}\right) Z_{C}=0 \\
& I_{22 F} \ell^{\Delta \alpha} Z_{R}+\left(I_{22 F} \ell^{\Delta \alpha}+I_{11 F} \ell^{\Delta \alpha}\right) Z_{\mu}+\left(I_{22 F} \ell^{\Delta \alpha}+I_{21 F} \ell^{\Delta \alpha}\right) Z_{C}=0
\end{aligned}
$$

Where

$$
\begin{aligned}
& Z_{S}=\left(\left(R_{1}+R_{\mu}\right)+J\left(X_{1}+X_{\mu}\right)\right), Z_{\mu}=(R \mu+J X \mu) \\
& Z_{R}=\left(R_{K}+J\left(X_{K}-X_{C}\right)\right), R_{K}=\left(R_{2}+R_{O}\right) / S, X_{K}=X_{2}+X_{O} \\
& Z_{C}=\left(\left(R_{M} / \sqrt{S}\right)+J\left(X_{M} / \sqrt{S}\right)\right)
\end{aligned}
$$

A difference in speeds of the syatem motors causes a difference in phase angles between the stator and rotor windings $\left(\alpha_{1}, \alpha_{2}\right)$. Therefore, it is possible to represent the difference in loads by the differences in phase angles. At equal loads, the phase angles will be equal too $\left(\alpha_{1}=\alpha_{2}\right)$, and $\Delta \alpha=[2][3]$. 
International Journal of Control Theory and Computer Modeling (IJCTCM) Vol.7, No.3/4, October 2017

If the first motor is considered as master and the second motor as slave, then:

$E_{21 F}=E_{2 F}, \quad E_{22 F}=E_{2 F} e^{j \Delta \alpha}, \quad S=S_{1}, \quad \Delta \alpha=\alpha_{1}-\alpha_{2}$

By considering $R_{1}=X_{1}=0$, according to [12], [15], [16] and after some mathematical manipulations, the final value of the forward current of the first motor may be found as:

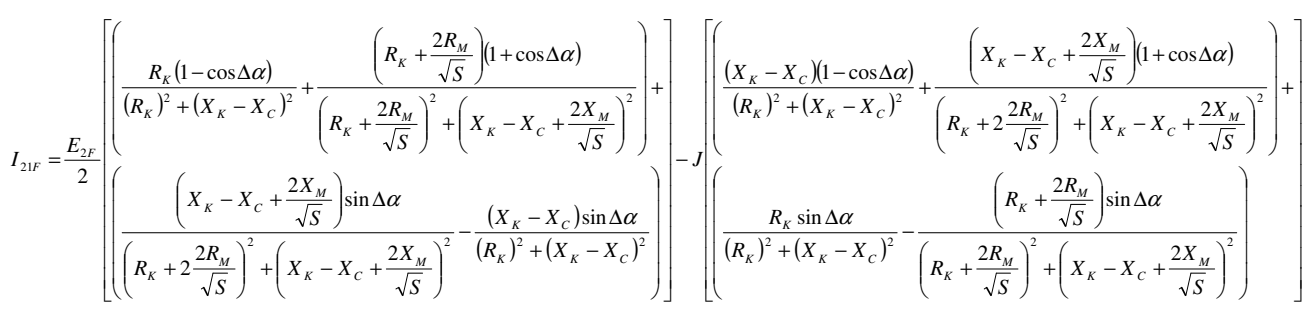

Based on the backward equivalent circuit, if the first motor is considered as master and the second motor as slave, the backward current of the first motor can be determined, similarly to the first motor, as:

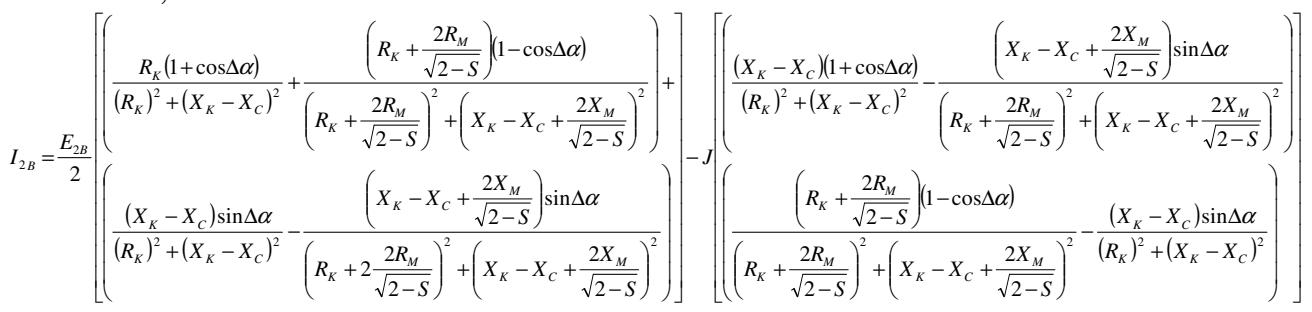

The total torque of the first motor may be calculated by the following formula [12], [13]:

$T_{1}=\frac{E_{2}}{2 \omega_{o}}\left[T_{1 F}-T_{1 B}\right]$

Where

$T_{1 F}=\frac{E_{2}}{2 \omega_{o}} I_{2 F(a c t)}$

$T_{1 B}=\frac{E_{2}}{2 \omega_{o}} I_{2 B(a c t)}$

$I_{2 F(a c t)}, I_{2 B(a c t)}$ are the active part of the forward and backward rotor currents respectively.

If the second motor is considered as master and the first motor as slave, the forward and backward currents of the second motor can be determined similarly to the first motor. The total torque of the second motor will be:

$$
\begin{aligned}
& E_{22 F}=E_{2 F}, \quad E_{21 F}=E_{2 F} e^{j \Delta \alpha}, \quad S=S_{2}, \quad \Delta \alpha=\alpha_{2}-\alpha_{1} \\
& T_{2}=\frac{E_{2}}{2 \omega_{o}}\left[T_{2 F}-T_{2 B}\right]
\end{aligned}
$$




\section{RESUltS AND ANALYSES}

The proposed mathematical model has realized using MATLAB/Simulink. Fig. 4 illustrates the speed curves of the motors of the electromagnetic synchronization system. These curves show the system response with different values of the factor $K_{m}=0.6,0.7$, and 0.8 [2] and with chaotic change in motors load of a maximum difference in loads of motors by $40 \%$. This factor $K_{m}$ depends on the value $R_{m}$, which is the main factor of determination of the electromagnetic element ( $R L$-element) dimensions. It is clear from these curves that the system goes into synchronism in all the three cases. At $K_{m}=0.6$ the system reached synchronism with short transient time (recovery time) which is about $3.5 \mathrm{~s}$. At $K_{m}=0.7$ the system reached synchronism with shorter recovery time, which is about $2 \mathrm{~s}$ only. At $K_{m}=0.8$ the system reached synchronism within about $4 \mathrm{~s}$, but in this case the speeds of the motors are oscillating about each other, as they have some overshoots and undershoots. The last response is not desirable, especially in applications with repetitive starting of the system. Therefore, if the value of factor $K_{m}$ exceeds the optimum value for synchronization, it will have a negative effect on the system response. The optimum value of the factor $K_{m}$ (and consequently, the dimensions of the $R L$-element) depends on the maximum possible difference in loads of the two motors, which is in the studied case is $40 \%$ with $K_{m}=0.7$, and in general it depends on the application.
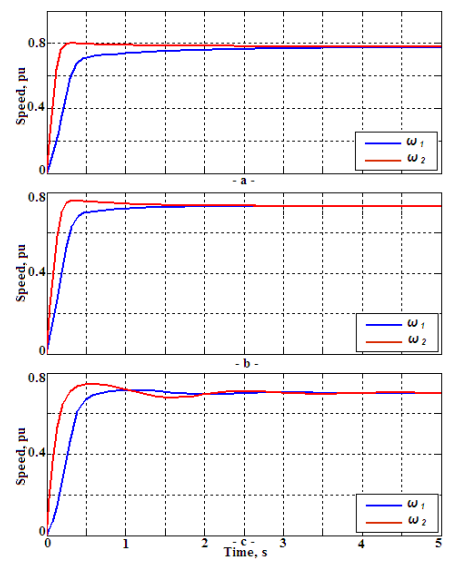

Fig. 4. Speed of the motors with $\mathrm{L} 1=1.4 \mathrm{~L} 2$ : a) $\mathrm{Km}=0.6$, b) $\mathrm{Km}=0.7$ and c) $\mathrm{Km}=0.8$

The next analyses and simulation are by considering the maximum possible difference in motor's load to be $40 \%$ and by keeping the factor constant $K_{m}=0.7$. Fig. 5 depicts the response of the motors of the studied system with $K_{m}=0.7, L_{1}=1.4 L_{2}$ and $d_{x}=0,0.5$ and $0.75 \mathrm{~mm}$. From the curves it is noticed that as the value of $d_{x}$ is increased as the recovery time is greater. This may be explained by the physics of changing the value of $d_{x}$. By increasing $d_{x}$ the continuous magnetic coupling between the rotor circuits of the two motors becomes weaker. Because of this the synchronization capability of the system becomes weaker and the system needs greater recovery time to go into synchronism. Also, it is clear from the curves that the motors will operate with lower speeds as the value of the $d_{x}$ is higher, regardless the other operational conditions. At the same time this change in speed with $d_{x}$ change may be used to control the speed to get speeds under the speed with $d_{x}=0$. 

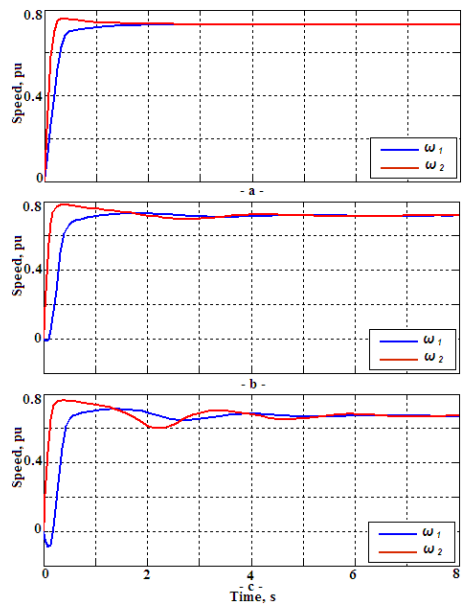

Fig. 5. Speed response of the motors with $\mathrm{L} 1=1.4 \mathrm{~L} 2, \mathrm{Km}=0.7$ : a) $\mathrm{dx}=0$, b) $d x=0.5$ and c) $d x=0.75 \mathrm{~mm}$

Curves in Fig. 6 show the starting of the motors with difference in loads of: a) $L_{l}=1.4 L_{2}$, b) $L_{1}=1.8 L_{2}$ and c) $L_{1}=2.4 L_{2}$. During the first four seconds the system goes into synchronism for all three cases with $d_{x}=0$. At $t=4 \mathrm{~s}$, the value of $d_{x}$ started to change gradually from zero up to $0.75 \mathrm{~mm}$ by small steps each of $0.05 \mathrm{~mm}$. In Fig. 6a, the change of $d_{x}$, with $40 \%$ difference in motor's loads, leads to smooth slowing down the speeds of both motors synchronously. In Fig. 6b, this change of $d_{x}$, with $80 \%$ difference in motors loads, leads to slowing down the speeds of both motors, but at first the motors lose synchronism for a short time (about 2s), then they go back into synchronism at lower speed. This shows that the increase of $d_{x}$ decreases the synchronization capability of the system. The oscillation in speeds and losing the synchronism for some interval of time appear, in this case, because the difference in loads is bigger. Fig. 6c shows similar response as in in Fig. 6b, but in a stronger manner, that because the difference in motors loads is $140 \%$. From the curves in Fig. 6, it is noticed that this kind of adjustment of air gap in order to get some speed regulation and control is suitable for such systems with difference in loads up to $40 \%$. While, for such systems with higher difference in loads, it will lead to some oscillations in motors speeds. The speed control that may be achieved by the proposed technique is applicable for lower speeds only.
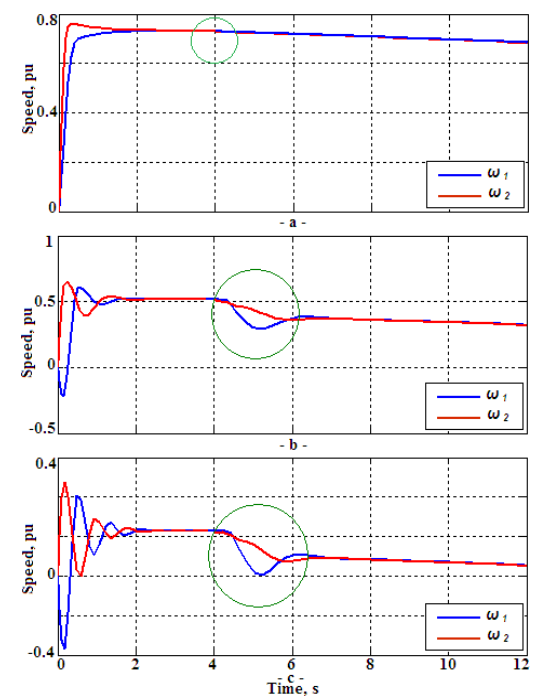

Fig. 6 . The speed response of the motors by changing the $\mathrm{dx}=0-0.75 \mathrm{~mm}$ at $\mathrm{t}=4 \mathrm{~s}$ : a) $\mathrm{L} 1=1.4 \mathrm{~L} 2$, b) $\mathrm{L} 1=1.8 \mathrm{~L} 2$, and c) $\mathrm{L} 1=2.4 \mathrm{~L} 2$ 
Fig. 7 shows starting of the motors with difference in loads of $L_{1}=1.38 L_{2}, K_{m}=0.7$, and $d_{x}=0$. After four seconds from starting as the system reached the steady-state conditions, the air gap $d_{x}$ has been increased gradually from zero up to $0.75 \mathrm{~mm}$ within four second. Then $d_{x}$ has been reduced gradually back to zero. From Fig. 7, it is clear that for such systems with relatively low difference in loads (up to $40 \%$ ) the suggested technique is suitable. The system has no oscillations, the motors stay in synchronism all the time and they operate at relatively high speed, which means that the slip is low and consequently the efficiency is high.

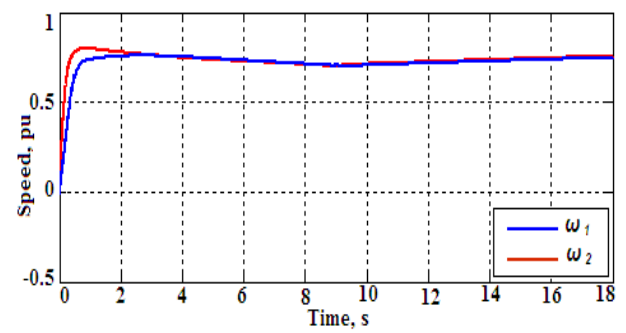

Fig. 7. The speed response of the motors with $\mathrm{L} 1=1.4 \mathrm{~L} 2$ by increasing $\mathrm{dx}=0-0.75 \mathrm{~mm}$ at $\mathrm{t}=4 \mathrm{~s}$ then decreasing it back to zero

\section{CONCLUSIONS}

Speed synchronization system of multiple single-phase induction motors can be achieved by using the traditional electromagnetic shaft synchronization system. The traditional electromagnetic shaft synchronization system has been modified by adding an adjustable air-gap within the core of the three-phase inductive rheostat element in the common rotor circuit. This makes it possible to control the speeds of the motors and regulate the synchronization capability or the recovery time of the system response (quality indicators). Analysis of the results shows that the suggested technique is suitable for systems with relatively low difference in the two motors loads. When the difference of the loads is up to $40 \%$, the system has no oscillations, the motors remain in synchronism all the time and they operate at relatively high speed, which means that the slip is low and, consequently, high efficiency. While, for systems with higher difference in motors' load, the air gap will lead to undesirable oscillations in the motors speeds.

\section{REFERENCES}

[1] F. Pkrez-Pinal, C. Alvarez, "Comparison of multi-motor synchronization techniques," Proceedings of IEEE Industrial Electronics Society Conference, pp. 1670-1675, 2004.

[2] A. Akayleh, E. Addasi, and S. Al-Jufout, "Speed synchronization of single-phase induction motors by electromagnetic shaft system," WSEAS Transactions on Systems and Control, vol. 11, pp. 425-430, 2016.

[3] A. Akayleh, "Mathematical model of capacitor effect on the synchronization systems," European Journal of Scientific Research, vol. 32, no. 1, pp. 34-42, 2009.

[4] A. Akayleh, E. Addasi, "Quality indicators of traditional synchronization systems," Jordan Journal of Electrical Engineering, Tafila Technical University, vol. 2, no. 2, pp. 172-180, 2016.

[5] A. Akayleh, E. Addasi, and S. Al-Jufout, "Speed control of multiple induction motors of electromagnetic shaft synchronization system," IEEE International Conference on Power and Energy, pp. 1-5, 2016. 
[6] A. Shukla, A. Kumar, A. Rajak, V. Singh, and S. Santhosh, "Speed synchronization of multiple dc motors in textile and paper mills using micro controller," Journal of Engineering Research and Applications, vol. 5, no. 5, pp. 52-55, 2015.

[7] Z. Bin, G. Feng, and L. Tian, "Normalized coupling method for speed synchronization of multi-axis driving vehicles," Advanced Robotic Systems, vols. 468-471, pp. 2227-2230, 2012.

[8] W. Chen, Y. Wu, R. Du, Q. Chen, and X. Wu, "Speed tracking and synchronization of a dual-motor system via second order sliding mode control," Mathematical Problems in Engineering, vol. 2013, pp. $1-10,2013$.

[9] A. Akayleh, A. Samarai, and M. Al-Soud, "Mathematical model of inductive effect on the multimotors synchronization systems," Jordan Journal of Mechanical and Industrial Engineering, vol. 3, no. 2, pp. 151-156, 2009.

[10] A. Akayleh, "Design and dimensions calculation of inductive rheostat as a control element of synchronization systems," Australian Journal of Basic and Applied Sciences, vol. 3, no. 4, pp. 37783785, 2009.

[11] D. Zhao, C. Li, and J. Ren, "Speed synchronization of multiple induction motors with adjacent cross coupling control joint," Proceedings of IEEE Conference on Decision and Control and 28th Chinese Control Conference, pp. 6805-6810, 2009.

[12] H. Zeroug, K. Boudjit, H. Kachroud, and H. Sahraoui, "Speed synchronization control of multiple dc motors using DSP," Proceedings of the European DSP in Education and Research Conference, pp. 47-51, 2010.

[13] N. Mitrovic, V. Kostic, M. Petronijevic, and B. Jeftenic, "Multi-motor drives for crane application," Advances in Electrical and Computer Engineering, vol. 9, no. 3, pp. 57-62, 2009.

[14] A. Akayleh, "Design and dimensions calculation of inductive rheostat as a control element of synchronization systems," Australian Journal of Basic and Applied Sciences, vol. 3, no. 4, pp. 37783785, 2009.

[15] Y. Pannatier, B. Kawkabani, C. Nicolet, A. Schwery, and J. Simond, "Start-up and synchronization of a variable speed pump-turbine unit in pumping mode," Proceedings of XIX International Conference on Electrical Machines, pp. 1-6, 2010.

[16] Z. Zhang, K. Chau, and Z. Wang, "Chaotic speed synchronization control of multiple induction motors using stator flux regulation," IEEE Transactions on Magnetics, vol. 48, no. 11, pp. 4487-4490, 2012.

[17] Z. Wang, K. Chau, and L. Jian, "Chaoization of permanent magnet synchronous motors using stator flux regulation,” IEEE Transactions on Magnetics, vol. 44, no. 11, pp. 4151-4154, 2008.

[18] A. Leicht and K. Makowski, "Analysis of a single-phase capacitor induction motor operating at two power line frequencies," Archives of Electrical Engineering, vol. 61, no. 2, pp. 251-266, 2012.

[19] E. Oluwasogo and I. Okakwu, "Performance Analysis of a single-phase AC voltage controller under induction motor load," International Journal of Research in Engineering and Technology, vol. 3, no. 6, pp. 184-191, 2014.

[20] R. Thinga, S. Gupta, and S. Phulambikar, "Field oriented control of single-phase induction motor," International Journal of Emerging Technology and Advanced Engineering, vol. 4, no. 8, pp. 760-763, 2014. 
International Journal of Control Theory and Computer Modeling (IJCTCM) Vol.7, No.3/4, October 2017

[21] Nandi, Gora Chand, et al. "Modeling bipedal locomotion trajectories using hybrid automata." Region 10Conference (TENCON),2016 IEEE. IEEE, 2016.

[22] Ehsan Abbasi.Development and implementation of adaptive fuzzy control system for a vtol vehicle in hovering mode, International Journal of Control Theory and Computer Modeling (IJCTCM) Vol.7, No.1/2, 2017.

[23] Dhikra Saoudi. Controller design based on fuzzy observers for T-S fuzzy bilinear models, International Journal of Control Theory and Computer Modeling (IJCTCM) Vol.6, No.1/2, 2016.

[24] Semwal, Vijay Bhaskar, and Gora Chand Nandi. "Toward developing a computational model for bipedal push recovery-A Brief." Sensors Journal, IEEE 15.4 (2015): 2021-2022 